\title{
The Iron Chancellor and the Fabian
}

\section{Le chancelier de fer et le fabianiste}

by ROBERT G. EVANS

\begin{abstract}
Adam Wagstaff (2009) reports on a statistical comparison of social health insurance (SHI) versus tax financed (TF) health systems within the OECD. On average, SHI financing is more expensive than TF and yields no better health outcomes. It lowers overall labour force participation and reduces the share of the formal sector. Why, then, is interest in SHI increasing in developing countries?

Consider the historical origins for SHI and TF. Bismarck (SHI) was a Prussian aristocrat; Beveridge (TF) was a socialist. TF is inherently egalitarian; SHI adapts readily to the preservation of inequality and privilege in both financing and access to care. This may be the real attraction of SHI in countries with highly unequal income distributions.
\end{abstract}

\section{Résumé}

Adam Wagstaff (2009) fait part d'une comparaison statistique entre, d'une part, le système d'assurance maladie sociale (AMS) et, d'autre part, le système de services de santé financés par les fonds publics (SFP), dans les pays de l'OCDE. En moyenne, le financement de l'AMS est plus coûteux que celui des SFP et ne mène pas à de meilleurs résultats en matière de santé. L'AMS réduit la participation globale de la maind'œuvre et diminue la part du secteur structuré. Pourquoi, donc, les pays en développement s'y intéressent-ils de plus en plus? 
Examinons les modèles historiques de l'AMS et des SFP : Bismarck (AMS) était un aristocrate prussien, Beveridge (SFP) était un socialiste. Les SFP représentent un modèle intrinsèquement égalitaire; l'AMS se prête plus facilement au maintien des inégalités et des privilèges, tant dans le financement que dans l'accès aux services. Cela constitue sans doute le véritable attrait de l'AMS dans les pays où la distribution des revenus est très inégale.

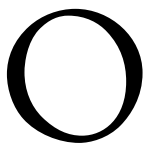
tto von Bismarck, the architect and first chancellor of the German Empire proclaimed in 1871, was not a closet social democrat. Yet he laid the foundations of the German welfare state, including in 1883 the world's first public health insurance system. This was financed through employer and employee contributions to locally administered agencies contracting with independent providers, though within a framework of tight government regulation. Variants of this "Bismarck model" have subsequently been widely adopted in many countries in the Organisation for Economic Co-operation and Development (OECD), as well as in developing countries and in the formerly Soviet economies of eastern Europe.

Sir William Beveridge, on the other hand, would clearly qualify as a social democrat by any definition. The economist from the London School of Economics laid out, in his classic 1942 report, the principles of the alternative "Beveridge model" that Nye Bevan institutionalized in the UK National Health Service. ${ }^{1}$ In this framework, both the financing and the provision of health systems are government responsibilities. Care may be delivered directly by governments, or on contract by more or less independent agencies; in either case, financing comes from general public revenue, raised through various forms of taxation rather than through contributions specific to the health insurance system. Again, variants of this model have spread across the world.

Although there are as many variants of these models as there are countries adopting them, and features from one model can be and are inserted into another, yet they remain the two distinct and recognizable alternative frameworks for providing public health insurance. No other fundamentally different models have emerged. Genuinely private health insurance, voluntary and unsubsidized, bought and sold in free markets, cannot cover more than a very small proportion of health expenditures. The reasons were made clear to economists by Akerlof (1970), though advocates of public insurance had understood them decades earlier. ${ }^{2}$ The options for financing health systems accordingly boil down to insurance coverage through some variant of the Bismarck or the Beveridge models, under their more modern labels of social health insurance (SHI) or tax finance (TF), or no coverage at all. This being so, the relative merits of these two alternatives become important matters, not only of intellectual debate but of practical health policy. 
Which brings us to a recent World Bank paper by Adam Wagstaff (2009). In an earlier paper he noted: "Social health insurance (SHI) is enjoying something of a revival in parts of the developing world" (Wagstaff 2007:1). There, he discussed in considerable detail the various claims and counter-claims by advocates for SHI and TF systems, with numerous country-specific examples. But in his more recent paper, he observes: "Like many intriguing and important debates, this one is being conducted on a flimsy evidence base" (Wagstaff 2009: 2), and he attempts to strengthen that base.

Wagstaff's 2009 paper is an empirical analysis of pooled data from 29 of the currently 30 members of the OECD over the period 1960-2006. ${ }^{3}$ The objective is to look for systematic differences between SHI and TF countries on various measures of health system performance.

The categorization is inevitably problematic in some cases; as he notes, "reforms during the 1990s and 2000s have left the distinction between the two models increasingly blurred" (Wagstaff 2009: 25). Increasing government intervention in SHI financing and administration leads towards a "Bismidgian" system, while contracting with more independent providers looks rather "Bevmarckian." Nevertheless, " $[t]$ he fundamental difference between SHI and tax-financed systems is that SHI systems raise revenues largely from earnings-related contributions levied largely on formal sector workers while tax-financed systems draw their revenues from taxes and nontax government revenues" (Wagstaff 2009: 6).

Of particular interest: during the study period a number of countries switched their dominant financing modes either from SHI to TF, or from TF to SHI. Eleven countries have maintained a SHI system throughout, while six (including Canada) maintained a TF system. Eight countries, however, switched from SHI to TF during the first half of the study period, while four, all formerly Soviet economies, switched from TF to SHI after the collapse of that system. ${ }^{4}$ These switches offer the possibility of identifying the effects of SHI or TF financing separately from the characteristics of particular countries.

Wagstaff's outcome measures are chosen from the various claims and criticisms made for and of these two financing alternatives, as well as on the availability of data. He estimates the impact of SHI relative to TF on health system costs, on the health outcomes achieved and on the overall national labour market.

On average, per capita health services costs (adjusted for purchasing power parities) are 3.5\% higher in SHI systems. The result is significant at the $1 \%$ level: SHI costs more. But does it deliver more? While TF advocates argue that TF systems are better able to contain overall health services costs, SHI advocates often regard this as a weakness, not a strength. Governments are either unwilling or unable to provide adequate funding; TF cost containment is therefore associated with poorer-quality care, insufficient to meet population needs.

To address these issues, Wagstaff (2009) draws on OECD Health Data estimates of 
rates of mortality from causes amenable to medical intervention, as well as recently published estimates by Nolte and McKee (2008). The motivation for such analyses is that while there are some causes of death that are simply beyond the reach of modern medical interventions, there are many others that are not. A person suffering from an "amenable" condition should not die from it if high-quality medical care is available. Thus the comparison of national health systems is (slightly) more fine-grained if the outcome measures are those for which medical care could, in principle, make a difference.

Moreover, since the well-known Fundamental Law of Epidemiology is that one out of one dies, comparisons are better made of deaths delayed, or conversely of "premature mortality." That term raises a host of questions - premature by whose standard? The OECD and Nolte and McKee (2008) operationalize it using Potential Years of Life Lost, or PYLLs. These are calculated by selecting a particular age cut-off and defining all deaths before that age as premature. The PYLL associated with each premature death is then the difference between the pre-selected cut-off age, and the actual age at death. Summing these across all deaths in a country over a given period yields the total PYLLs for that country; these can then be categorized by cause of death and identified as "amenable" or otherwise.

Wagstaff compares PYLL rates for nine different causes of death that are identified as amenable to medical intervention in both the OECD tabulations and in Nolte and McKee's (2008) analysis: malignant neoplasms of the colon and rectum (ICD10 C18-21); malignant neoplasm of the breast (females only) (C50); malignant neoplasm of the cervix uteri (females only) (C53); diabetes (E10-4); ischaemic heart disease (ICD10-I20-5); cerebrovascular disease (I60-9); influenza and pneumonia (J10-28); maternal death (O00-99); and perinatal deaths other than stillbirths (P00-96). A simple bivariate comparison of these PYLL rates in SHI countries with those in TF countries showed that rates were higher (worse outcomes) in SHI countries for six of these conditions, and lower in three.

As Wagstaff (2009) emphasizes, however, these comparisons may have little or no meaning because of the host of other factors affecting mortality rates that will vary, probably widely, across countries. More generally, any observed relation between variables $\mathrm{A}$ and $\mathrm{B}$ may arise because $\mathrm{A}$ causes $\mathrm{B}$, or B causes $\mathrm{A}$, or a third factor affects both $A$ and $B$, or simply by chance. A very substantial part of the paper is devoted to various econometric techniques for testing and controlling for the influence of potential confounders - country- and time-specific effects of excluded variables masquerading as SHI or TF effects - as well as to the possibility of "reverse causality," in which the presence or absence of SHI might be the consequence, not the cause, of country differences in costs, outcomes or both.

These tests and techniques generate a number of results that, though important, are primarily of technical interest. In the end, Wagstaff concludes that after adjusting for potential confounding effects, there is in fact no statistically significant evidence for dif- 
ferences in health outcomes between SHI and TF countries within the OECD - with one exception. Breast cancer mortality rates among women are significantly higher in SHI countries, by an estimated 5\% to 6\%. Wagstaff (2009) describes this finding as "not implausible" in the light of other studies showing that TF systems, because of their focus on the whole population rather than individual enrollees, tend to provide better comprehensive national public health programs in general, and cancer screening in particular.

The key point for Wagstaff, however, is that these data offer no support for any claim that SHI systems yield, on average, better health outcomes in return for their higher costs. It might be noted in passing that the estimated 3.5\% extra costs per capita in SHI systems are, like the health outcome estimates, the product of extensive econometric adjustment for excluded factors. A simple comparison of mean costs per capita shows SHI countries to cost, on average, almost twice as much. Nearly all of that difference is estimated to be due to the effects of other factors not explicitly accounted for in the analysis. But when these are all pared away, there remains a (statistically) significant extra cost for SHI systems, with no benefit in terms of health outcomes.

Data on measures of health system utilization, such as hospital admissions or physician visits, were not sufficiently complete or comprehensive to include in the crosscountry comparisons. In any case if one found, as one might expect, that higher costs were associated with greater activity levels, this would not seem a priori to represent an advantage for $\mathrm{SHI}$ in the absence of corresponding improved health outcomes.

It is worth noting that Watson and McGrail (2009; this issue of Healthcare Policy), using Nolte and McKee's (2008) data, have shown that while Canada has one of the lowest ratios of physicians to population in the OECD - a fact stressed by those asserting a severe physician shortage - it suffers no disadvantage in PYLL from amenable causes and indeed achieves among the best results in the OECD. This fact has gone unnoticed by the media. There is extensive and powerful evidence that, in the United States at least, higher capacity and activity levels, and higher costs, not only yield no health benefits at the population level but are actually associated with poorer health outcomes. ${ }^{5}$

The relative impact on labour markets of alternative methods of health services finance has received little attention from health economists, but has certainly not escaped the attention of labour economists. Standard economic theory, and indeed common sense, would suggest that linking contributions to employee earnings discourages employment. Further, to the extent that this extra cost can be avoided if workers move into the informal sector, SHI would tend to shift the balance of employment away from the formal sector.

Wagstaff (2009) finds quite a strong effect of SHI on labour markets. On average, SHI lowers the overall employment rate among workers aged 15 to 65 by $5 \%$ to $6 \%$, and lowers the proportion of those workers who are in the formal sector by $8 \%$ to $10 \%$. Both these effects lower the overall productivity of the economy; they represent 
additional costs of SHI relative to TF that never turn up explicitly on anyone's budget.

These labour market responses can have significant implications for the extent of coverage achieved by SHI systems, and the associated costs. Whether participation is voluntary or nominally compulsory for workers in the informal sector, de facto levels of coverage typically fall very far short of universality. Wagstaff (2009) notes that even in highly developed economies with a long history of SHI - Germany and Japan, for example - universality was an objective in principle but took decades to achieve. "Universality" is difficult or impossible to achieve through a patchwork of SHI plans. Significant portions of the population inevitably fall through the cracks, and the terms of coverage - the costs of enrolment and the quality of care - vary considerably among the different plans. In fact, given the numerous country-specific examples of structured inequalities in coverage and care described in the two Wagstaff papers, it is quite surprising that (almost) no systematic differences emerge in health outcomes, and that the additional costs associated with SHI are not greater.

Given these disadvantages, why would there be a renewal of enthusiasm for SHI finance in various parts of the world? This brings us back to the Iron Chancellor.

Bismarck had a number of reasons for introducing his welfare state legislation. For one thing, "Staatsocialismus" took a powerful issue away from the socialists, who were particularly strong in Germany. ${ }^{6}$ And a healthy population provides more productive workers and better soldiers. Further, he may have been genuinely concerned that loyal and responsible workers could be reduced to abject poverty by illness or old age.

"Solidarity" was from the outset a fundamental principle of the German welfare state. It is symbolized in the room reconstructed from that originally built as the administrative courtroom for the social insurance system in 1883. Preserved from the original structure and overlooking the room are four sculpted heads, one at each corner of the ceiling. One is a boy, another a young man, another a mature man and the fourth, an old man. It was hoped that the rulings made in this venue would reflect the fundamental principle of intergenerational social solidarity. ${ }^{7}$

But an egalitarian Bismarck was not. Solidarity across the generations, yes, but within a rigid class structure - the solidarity of an army, with very well-defined ranks and privileges, and a sharp divide between officers and men. The structure of the German health insurance system is well adapted to reflecting and maintaining these class distinctions. As it does today - higher-income citizens can opt out of the general system of Krankenkassen and make their own private arrangements - with corresponding access to preferred forms of care.

Beveridge, on the other hand, did have an egalitarian bent, reflected in the system that bears his name. Since everyone pays taxes, everyone is automatically enrolled in TF systems, and contributions are more or less proportionate to income, regardless of how that income is earned. Correspondingly, everyone has in principle access to the same array of publicly provided health services "on equal terms and conditions" 
- though in practice there may be extraordinary geographic inequities in provision. Some countries (United Kingdom) permit those willing and able to pay to "go private" and purchase for themselves more timely or perceived higher-quality care; ${ }^{8}$ others (Canada) try with varying energy to discourage this. But citizens cannot opt out of paying the taxes that support the public system.

In a classic SHI system, contributions are based on wage and salary income only, and there may, as in Germany, be a ceiling on total contributions. SHI systems are thus typically more regressive in their financing; the better-off contribute a smaller share of their incomes, even if they do not opt out entirely. Where there are a number of different SHI funds, the level of required contributions may vary considerably, depending on the relative health status or the average incomes of fund members. And whatever the public rhetoric of universality, the marginalized members of society (not Bismarck's loyal and responsible workers) are very likely to be left out entirely.

Mature SHI systems have evolved to mitigate these inherent inequities. The French system, for example, has extended the SHI contribution base to include all forms of income, and does not place a ceiling on contributions; the German and Dutch systems have extended general revenue funding (TF) to supplement the SHI funds. But estimates of the progressivity or regressivity of different national systems (Wagstaff et al. 1999, now sadly in need of updating) show marked differences in the extent to which various national systems transfer resources from higher- to lowerincome groups. The German financing system, for example, is much more regressive than that of the British - or the French.

In short, relative to TF, SHI financing limits the extent of redistribution down the income spectrum that tends to follow expanded health insurance coverage, while preserving privileged access for the better-off and strategically placed occupational groups. This approach might be extremely attractive to elites in countries with highly unequal income distributions, as in much of South America. Providing care to the whole population at a standard acceptable to, say, the top quartile would involve a very substantial tax burden at the upper end of the income distribution - after all, that's where the money is. The attraction of SHI in developing countries may be precisely that it permits segregation of the population in terms of access to and quality of care, and distributes the burden of payment regressively. ${ }^{9}$

Such distributional benefits are well worth a bit of extra cost. Besides, all those extra costs are paid to someone. Advocates argue that SHI systems are not under direct government control, and their funding is thus less "vulnerable ... to the whimsical nature of governments" (quoted in Wagstaff 2007: 10). Moreover, there are allegedly inherent limits to the taxing capacity of governments, limits that are somehow less binding when taxes are on payrolls, not incomes.

Canadians will be very familiar with this line of argument after 40 years of claims that our health system is "underfunded," and more recent claims that universal pub- 
lic health insurance is "unsustainable." Here too, governments are allegedly incapable of raising sufficient funds through taxation to meet the population's growing needs. Opening up private payment, however, supported of course by private insurance with a large public subsidy, would allegedly permit adequate funding of this chronically "underfunded" system - that is, higher costs.

The real attraction of SHI would appear to be that it shields health spending, to some degree at least, from direct accountability to elected governments, while on average providing a larger flow of total income to providers of care and administrators of payment systems. Since at the same time it can be structured to offer greater benefits to the upper end of the income spectrum at lower cost (to them) than a TF system, the reasons for growing interest are obvious. Wagstaff's (2009) findings that SHI costs more, yields no better average health outcomes, reduces participation in the formal labour force and, in developing countries, typically falls far short of universality, seem a small price to pay.

\section{NOTES}

1. Hacker (1998) traces the intellectual and institutional roots of the Beveridge model back to Lloyd George's National Insurance Act of 1911, arguing that this was the key political turning point.

2. Those enjoying a rich fantasy life - including marketophile economists - may amuse themselves by constructing hypothetical schemes for providing universal health insurance through voluntary private markets. These crumble under any serious analysis. They can, however, be very useful in distracting and delaying serious health system reforms.

3. Wagstaff (2009: 5) excludes the United States on the grounds that it "relies largely on private insurance and out-of-pocket payments ... ." This is not strictly accurate; American governments actually cover about $60 \%$ of health expenditures either directly or through subsidies to private insurance. A better justification is Ted Marmor's insight (personal communication) that the United States has several distinct subpopulations, each under a different model of coverage (or none at all).

4. "Switching" is a rather colourless term for a more complex process. Sweden is included as moving from SHI to TF, but the centralized public delivery system did not change - only the revenue source. The four formerly Soviet economies had in fact been within the German orbit prior to occupation by the Red Army, and had been developing SHI systems; they might be seen as returning after an extended perturbation.

5. These data, coming in particular from the research group at Dartmouth, have suddenly burst onto public and presidential consciousness through a remarkable essay by Gawande (2009). 
6. Substitute "national" for "state," and Bismarck's term has a horribly prophetic ring. Bismarck would have been appalled by Hitler for many reasons, and would probably have squashed him like a bug. Unintended consequences?

7. From Rice et al. (2000: 864), with minor edits.

8. This private option is inconsistent with the Beveridge principles; it was a concession to political realities when the UK NHS was founded. In every country, the political representatives of the better-off strive to establish, maintain and expand the privileges inherent in "two-tier" healthcare.

9. The attraction in eastern Europe may be simply a revulsion against anything from the Soviet period.

\section{REFERENCES}

Akerlof, G.A. 1970 (August)."The Market for 'Lemons': Qualitative Uncertainty and the Market Mechanism." Quarterly Journal of Economics 84(3): 488-500.

Beveridge, W. 1942. Social Insurance and Allied Services. London: His Majesty's Stationery Office. Retrieved June 22, 2009. <http://www.almendron.com/politica/pdf/2009/9119.pdf>.

Gawande, A. 2009 (June 1). "The Cost Conundrum: What a Texas Town Can Teach Us about Health Care." The New Yorker. Retrieved June 22, 2009. <http://www.newyorker.com/ reporting/2009/06/01/090601fa_fact_gawande $>$.

Hacker, J.S. 1998 (Spring).“The Historical Logic of National Health Insurance: Structure and Sequence in the Development of British, Canadian and US Medical Policy." Studies in American Political Development 12: 57-130.

Nolte, E. and C.M. McKee. 2008 (July/August)."Measuring the Health of Nations: Updating an Earlier Analysis." Health Affairs 27(1): 58-71. Retrieved June 22, 2009. < http://content.healthaffairs.org/cgi/content/abstract/27/1/58>.

Rice, T., B. Biles, E.R. Brown and F. Diderichsen. 2000 (October)."Reconsidering the Role of Competition in Health Care Markets: Introduction." Journal of Health Politics, Policy and Law 25(5): 863-72.

Wagstaff, A. 2007 (January). “Social Health Insurance Reexamined." Policy Research Working Paper \#4111. Washington, DC: The World Bank.

Wagstaff, A. 2009 (January). "Social Health Insurance vs. Tax-Financed Health Systems Evidence from the OECD." Policy Research Working Paper \#4821. Washington, DC: The World Bank.

Wagstaff, A., E. van Doorslaer, H. van der Burg et al. 1999."Equity in the Finance of Health Care in Twelve OECD Countries." Journal of Health Economics 18(3): 263-90.

Watson, D. and K.M. McGrail. 2009 “More Doctors or Better Care?” Healthcare Policy 5(1): 26-31. 